\title{
Patient expectations and experiences of multiple sclerosis interferon $\beta$ - la treatment: a longitudinal, observational study in routine UK clinical practice
}

This article was published in the following Dove Press journal:

Patient Preference and Adherence

17 February 2014

Number of times this article has been viewed

\author{
Mehmood Syed' \\ David Rog ${ }^{2}$ \\ Laura Parkes ${ }^{3}$ \\ Gillian L Shepherd ${ }^{3}$ \\ 'Bupa Home Healthcare, Harlow, \\ Essex, ${ }^{2}$ Department of Neurology, \\ Greater Manchester Neurosciences \\ Centre, Salford Royal NHS \\ Foundation Trust, Salford, ${ }^{3}$ Medical \\ Affairs, Merck Serono Ltd, Feltham, \\ Middlesex, UK
}

Background: Premature discontinuation and poor treatment adherence are problems in chronic conditions, such as multiple sclerosis in which patients must take long-term treatment in order to receive maximum benefit from their medication. The Assessing needs In Multiple Sclerosis (AIMS) study explored factors related to premature treatment discontinuation and patients' experiences of subcutaneous (sc) interferon (IFN) $\beta$-1a treatment in the UK.

Methods: A questionnaire-based survey was integrated into the Bupa Home Healthcare patient-support program, which delivers sc IFN $\beta$-1a to patients in their home. Data were collected via patient questionnaires incorporated into routine clinical care and administered upon registration of a new patient by the coordinator, following initial delivery of treatment, prior to each delivery during therapy and at the end of treatment. Univariate and multivariate analyses were performed to identify factors associated with premature discontinuation.

Results: Data were collected from 2,390 patients (1,267 new; 1,123 existing) from 59 UK prescribing centers (November 2006-April 2011). Following the first delivery of sc IFN $\beta$-1a, $94 \%(1,149 / 1,225)$ of patients had received training, and $73 \%(818 / 1,120)$ reported that they had no concerns. In total, $24 \%$ of new patients discontinued therapy by the end of the study. In the univariate model, none of the candidate variables tested were significant predictors of treatment discontinuation. The strongest predictors of discontinuation in multivariate analyses were lack of information prior to starting treatment and patients feeling unwell on treatment and geographic region $(P<0.05$ for each variable).

Conclusion: This study suggests that patients feeling well on treatment and provision of high-quality information are the main determinants of persistence with sc IFN $\beta$-1a therapy. A package of care that targets these issues should therefore be considered when initiating sc IFN $\beta$-1a therapy.

Keywords: multiple sclerosis, interferon $\beta$-1a, drug delivery, adherence, persistence

\section{Introduction}

Multiple sclerosis (MS) is a chronic, inflammatory, demyelinating disease of the central nervous system. ${ }^{1}$ Relapsing-remitting MS (RRMS) is characterized by episodes of acute worsening of neurologic function, associated with magnetic resonance imaging plaques in the brain and/or spinal cord, ${ }^{2}$ followed by a variable degree of recovery, with a stable course between attacks. ${ }^{3}$ The target of current disease-modifying drugs (DMDs) for MS is to prevent plaque formation, decrease the rate and severity of relapses, and delay resulting disability. ${ }^{4}$

In developed countries, treatment adherence to long-term therapies is estimated to be as low as $50 \%$ in patients with chronic illness. ${ }^{5}$ The reasons for poor adherence or treatment discontinuation in MS include side effects, injection anxiety, patient
Correspondence: Mehmood Syed Clinical Programmes Director, Hearst Health International, Dubai Media City, Dubai, United Arab Emirates

Tel +97I 528818750

Email mehmood.syed@mapofmedicine. com 
choice, pregnancy, and lack of efficacy. ${ }^{6-8}$ Lack of adherence to DMDs for MS can lead to poorer patient outcomes and decrease the efficiency of health care services. ${ }^{9}$

An important component of poor adherence is premature treatment discontinuation. It is known that the first 2 years of treatment are a critical period for treatment discontinuation in patients receiving DMDs. ${ }^{6}$ However, rates of treatment persistence are generally higher in clinical trials than in clinical practice owing to trial participants being more motivated and receiving more encouragement to use their therapy through more frequent contact with study staff per protocol. ${ }^{10}$ Strict selection criteria and study procedures in randomized controlled trials can also be a source of bias.

The assessing needs in MS (AIMS) study explored factors related to premature treatment discontinuation, and patients' experiences while receiving subcutaneous (sc) interferon (IFN) $\beta$-1a (Rebif ${ }^{\circledR}$; Merck Serono Europe Limited, London, UK, an affiliate of Merck KGaA, Darmstadt, Germany) therapy in routine UK clinical practice. The AIMS study was integrated into the Bupa Home Healthcare patient support program, which is widely used in the UK to deliver DMDs to patients with MS in their homes. Identifying risk factors for treatment discontinuation may aid the design of future interventions to encourage adherence and potentially improve clinical outcomes.

\section{Methods}

\section{Study design}

The AIMS study was a longitudinal questionnaire-based survey of patients with MS from the UK receiving sc IFN $\beta-1 \mathrm{a}$ in a real-world setting, with systematic collection of patient-centric information achieved in line with routine MS clinical care. Participants were contacted by Bupa Home Healthcare's MS Patient Coordinators by telephone. Data collection was incorporated into routine clinical care at four stages of the support program: at registration of a new patient by the coordinator (pre-installation), following initial delivery of treatment (post-installation), prior to each 4-weekly delivery during therapy (pre-delivery) and at the end of treatment (Figure 1).

The study was conducted through routine patient contact, with no additional contacts made with the patient for the purpose of the study other than to follow-up on patient consent at the study start (as per the study design approved by the National Research Ethics Committee). Data were collected by homecare patient coordinators using a scripted conversation based on the structured questionnaire. The data were then anonymized by removing the patient's personal and demographic

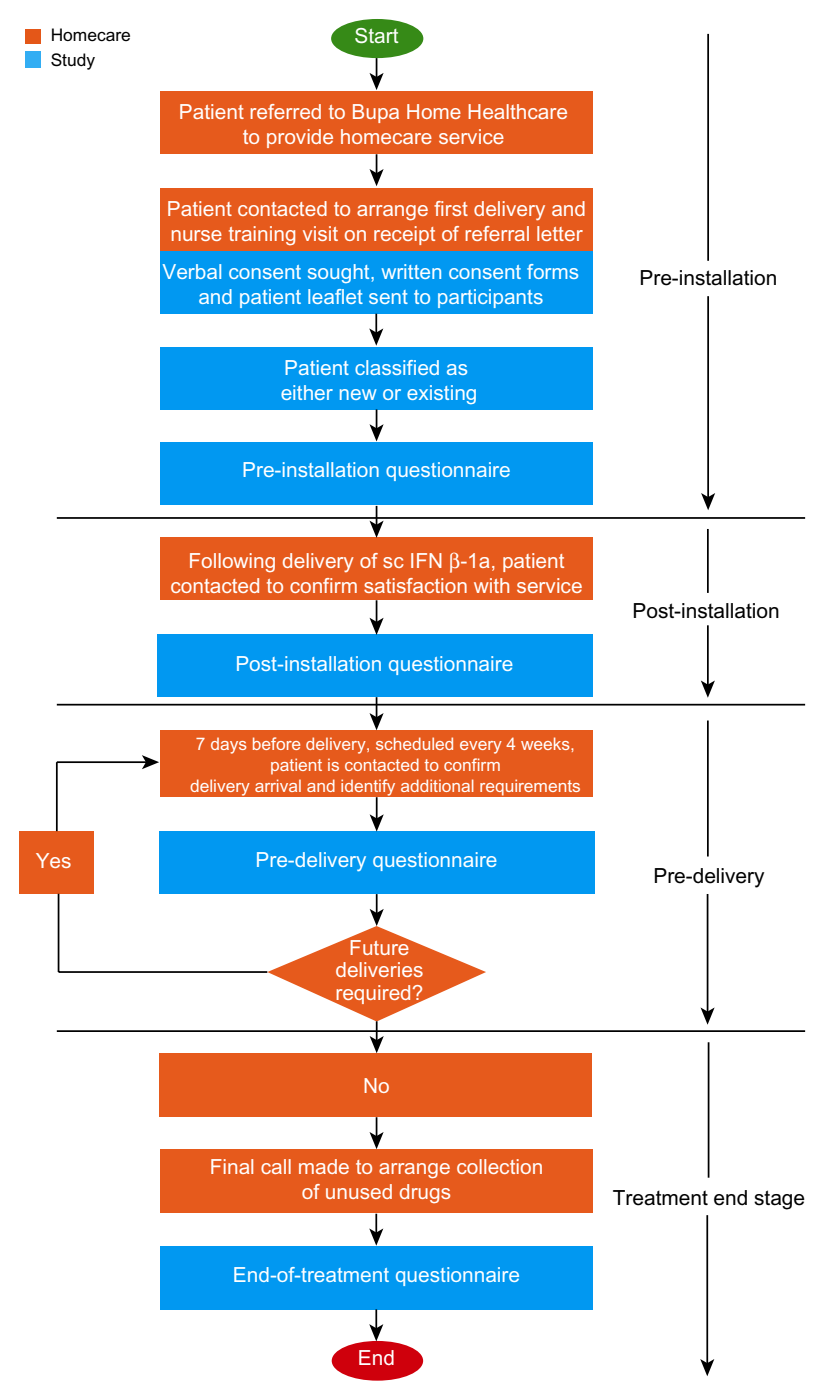

Figure I Key stages of multiple sclerosis treatment with IFN $\beta$ - Ia through the Bupa Home Healthcare service, and data collection in the AIMS program.

Abbreviations: AIMS, Assessing needs in Multiple Sclerosis; IFN, interferon; sc, subcutaneous.

details and replacing with a patient identification number. The database for the study was maintained separately from the main Bupa Home Healthcare management system. Data were reviewed on a weekly and monthly basis throughout the study period and at the end of the study to control for missing fields (missing data were discounted from the analysis).

\section{Patients and study populations}

Eligible patients comprised all UK National Health Service (NHS) patients (aged $\geq 16$ years) who had been prescribed sc IFN $\beta$-1a $\left(\right.$ Rebif $\left.^{\circledR}\right)$, three times weekly, as per the summary of product characteristics; $;{ }^{11}$ these patients were identified by a referral center to the Bupa Home Healthcare service, which provides the majority of home health care support for patients receiving sc IFN $\beta$-1a in the UK. Patients were withdrawn 
from the study if their clinic stopped prescribing sc IFN $\beta$-1a or if they were referred to a different homecare provider.

The "new" patient population consisted of patients who were naïve to sc IFN $\beta$-1a treatment; unless stated otherwise, all analyses were carried out on this population. The "existing" patient population (recruited to gather more data related to experience on treatment) consisted of patients who were already receiving sc IFN $\beta$-1a. The "all patient" population comprised both new and existing patients.

\section{Standard protocol approvals, registrations, and patient consent}

The AIMS study (NCT01080573) was performed in accordance with the protocol and applicable local regulations, and conformed with the Declaration of Helsinki. The study was approved by the National Research Ethics Service and was granted full multicenter research ethics committee approval. Local Research and Development approval was granted from 62 participating UK NHS Trust hospitals (at the end of the recruitment period, three centers had recruited no patients).

Verbal consent was obtained during Bupa Home Healthcare's first contact with the new patients or at the next scheduled contact for existing patients. Patients consenting verbally to inclusion in the study were mailed a copy of the patient leaflet and an informed consent form to sign and return. To ensure a complete dataset, data were collected from the patient during the period between verbal and written consent, as agreed with the patient and in accordance with the ethics committee approval. Patients who initially provided verbal consent but withdrew or did not provide written consent within the 6-week period - a stipulation of the ethics approval - and patients who withdrew written consent were removed from the database. All patients remained eligible for the homecare service. No safety data were collected during this study.

\section{Study size}

Assuming that $10 \%$ of patients would not continue treatment, and in order to detect a 5\% difference in persistence between patients who did and did not feel well informed (5\% significance at $80 \%$ power), 1,258 new patients were required.

\section{Study endpoints}

The primary endpoints were the characteristics of patients who stopped treatment compared with patients who continued treatment in the all patient population, and the risk factors for premature discontinuation of sc IFN $\beta$-1a treatment in the new patient population. Secondary endpoints were additional associations between questionnaire responses and a summary of the questionnaire responses.

\section{Statistical analyses}

Descriptive statistics for the new patient population were used to summarize questionnaire responses and, for predelivery questions, were provided also at 0-6 months, 6 months-1 year, 1-2 years, and more than 2 years after treatment start date. Treatment experience was measured as an ordinal variable ( $1=$ good, $5=$ very poor). Candidate variables, including age, sex, geographical region of the UK, previous use of DMDs, whether the patient had received information from the clinic, degree to which patients felt informed about treatment, degree to which patients were looking forward to therapy, whether any decision to discontinue a previous therapy was taken by the patient, level of information received during therapy, and patient experience on therapy were analyzed using univariate survival analysis to identify potential predictors of treatment discontinuation. In addition, Kaplan-Meier curves were drawn for each level of each of these candidate variables.

All variables that were used in the univariate analysis were also analyzed using a multivariate analysis of the new patient population (Cox proportional hazards regression using a stepwise procedure: inclusion level 0.1 , exclusion level 0.15). The extended model was used, as some variables were time-dependent. All pair-wise comparisons of variables were considered: if two variables were highly correlated (Pearson correlation coefficient $\geq 0.4$ ), one was excluded from the multivariate model.

A degree of information score was computed for each patient averaging his responses to "How well informed do you feel?" during the treatment period (extremely $=1$, very $=2$, $\mathrm{OK}=3$, not very $=4$, or uninformed $=5$ ); this mean score was used to classify patients into two groups: well informed (mean score $<3.0$ ) or not well informed (mean score $\geq 3.0$ ); unpaired $t$-tests, performed because of the test's robustness in ordinal scale variables, ${ }^{12}$ were used to compare the mean response to "How have you found taking your treatment this month?" between the two groups. In addition, patients were split into two groups based on their response to "How well informed do you feel?" at pre-installation (extremely, very, or OK versus not very or uninformed); the mean response to "How have you found taking your treatment this month?" (ordinal variables as above) was compared between the two groups at start of therapy- 6 months, 6 months -1 year, 1 year-2 years, or $>2$ years using an unpaired $t$-test. 


\section{Post hoc analyses}

Social and economic deprivation was calculated using the Indices of Multiple Deprivation in England, Wales, and Scotland. For the purpose of univariate (Kaplan-Meier) and multivariate analyses (Cox proportional hazards regression using an alternate forward selection and backward elimination stepwise procedure: inclusion level 0.1 , exclusion level 0.15 ) of treatment discontinuation, patients in each country were stratified into less deprived or more deprived.

Responses at pre-installation to "Has your clinic given you any information about your treatment yet?" and "How well informed do you feel?" or "Degree to which patients were looking forward to therapy" were analyzed with MantelHaenszel tests. SAS System (version 9.2; SAS Institute Inc, Cary, NC, USA) was used for the statistical analyses.

\section{Results}

\section{Patient disposition and demographics}

Between November 2006 and April 2011, 2,390 patients were enrolled, of whom 1,267 were new and 1,123 were existing patients. Patients' demographic characteristics are listed in Table 1.

Table I Patient demographic and characteristics

\begin{tabular}{|c|c|c|c|}
\hline Characteristic & $\begin{array}{l}\text { Existing } \\
\text { patients } \\
(n=I, I 23)\end{array}$ & $\begin{array}{l}\text { New } \\
\text { patients } \\
(n=1,267)\end{array}$ & $\begin{array}{l}\text { All } \\
\text { patients } \\
(\mathrm{N}=2,390)\end{array}$ \\
\hline Mean (SD) age, ${ }^{a}$ years & $43.6(8.93)$ & $39.9(9.30)$ & $4 I .6(9.31)$ \\
\hline Age range, years & $21-73$ & $16-76$ & $16-76$ \\
\hline \multicolumn{4}{|c|}{ Age $^{a}$ (categorized by years), n (\%) } \\
\hline$<25$ & $\mathrm{II}(<\mathrm{I})$ & $6 \mathrm{I}(5)$ & $72(3)$ \\
\hline $25-34$ & $170(15)$ & $292(23)$ & $462(19)$ \\
\hline $35-44$ & $447(40)$ & $525(4 I)$ & $972(4 I)$ \\
\hline $45-54$ & $350(31)$ & $312(25)$ & $662(28)$ \\
\hline $55-64$ & $135(12)$ & $71(6)$ & $206(9)$ \\
\hline$\geq 65$ & $10(<1)$ & $6(<1)$ & $16(<1)$ \\
\hline \multicolumn{4}{|l|}{ Sex, n (\%) } \\
\hline Female & $872(78)$ & $\mathrm{I}, 020(8 \mathrm{I})$ & I,892 (79) \\
\hline Male & $25 \mathrm{I}(22)$ & $247(19)$ & $498(2 I)$ \\
\hline \multicolumn{4}{|l|}{ Region, n (\%) } \\
\hline East Midlands & $116(10.33)$ & II $4(9.00)$ & $230(9.62)$ \\
\hline East of England & $120(10.69)$ & $106(8.37)$ & $226(9.46)$ \\
\hline London & $19(1.69)$ & $55(4.34)$ & $74(3.10)$ \\
\hline North East & $123(10.95)$ & $101(7.97)$ & $224(9.37)$ \\
\hline North West & $|4|(12.56)$ & $177(13.97)$ & $318(13.31)$ \\
\hline Scotland & $126(11.22)$ & $100(7.89)$ & $226(9.46)$ \\
\hline South Central & $94(8.37)$ & $108(8.52)$ & $202(8.45)$ \\
\hline South East Coast & $52(4.63)$ & $55(4.34)$ & $107(4.48)$ \\
\hline South West & $55(4.90)$ & $102(8.05)$ & $157(6.57)$ \\
\hline West Midlands & $152(13.54)$ & $193(15.23)$ & $345(14.44)$ \\
\hline Yorkshire and Humber & $125(11.13)$ & $156(12.31)$ & $281(11.76)$ \\
\hline
\end{tabular}

Note: a Age of patient on date of pre-delivery assessment. Abbreviation: SD, standard deviation.
The number of patients enrolled in the AIMS study accounts for $15.7 \%(2,390 / 15,267)$ of the estimated number of patients with MS receiving DMDs through homecare companies (Bupa Home Healthcare, Healthcare at Home, and Evolution Homecare, which provide the majority of DMD treatments prescribed on the NHS to patients with MS) in the UK as of April 2011. Of the 5,450 patients approached to take part in the study, 2,722 (49.9\%) provided written consent. Overall, $24.0 \%(304 / 1,267)$ of new patients and 30.0\% $(341 / 1,123)$ of existing patients discontinued therapy during the study; the mean (standard deviation [SD]) follow-up was 18.1 (11.8) months.

\section{Pre-study characteristics of patients who did and did not stop treatment (primary endpoint)}

There were no notable differences in the pre-study characteristics (excluding geographical region), use of a patient support line, and duration of time receiving sc IFN $\beta$-1a between patients who did and did not stop treatment in the new or existing patient populations. Results for new patients are shown in the Supplementary materials (Table S1).

\section{Questionnaire responses (new patients)}

Data on responses to pre-installation, post-installation, predelivery, and end-of-treatment questions are shown in the Supplementary materials (Tables S2-S5).

\section{Information provision}

At the start of the study, $81 \%(1,006 / 1,249)$ of patients had received information about treatment from their clinic, and $44 \%(553 / 1,265)$ felt extremely or very well informed. Following the first delivery of sc IFN $\beta$-1a, $94 \%(1,149 / 1,225)$ of patients had received training and $96 \%(1,128 / 1,179)$ of those who provided a response felt they had received sufficient training; $85 \%(1,018 / 1,192)$ of patients who had received training did so from their hospital. In total, $62 \%$ $(766 / 1,238)$ of patients had received most of their information from the hospital, $21 \%(254 / 1,238)$ from the internet, and $6 \%(70 / 1,238)$ from patient support groups. Responses given at 6 months and $>2$ years to information provision questions prior to the repeat delivery of sc IFN $\beta$-1a are shown in Table 2. Responses given at intermediate time points are consistent with those at 6 months and $>2$ years.

Of the patients who ended treatment, 35\% (108/311) of responses were "not at all" to the question "Did you contact any support lines during your treatment?" 
Table 2 Information provision and treatment experience responses during the study

\begin{tabular}{|c|c|c|c|}
\hline Question & Response & $\begin{array}{l}\text { Treatment } \\
\text { period }\end{array}$ & $\begin{array}{l}\text { Proportion of } \\
\text { responses, \% } \\
(\mathrm{n} / \mathrm{N})\end{array}$ \\
\hline \multicolumn{4}{|c|}{ Information provision } \\
\hline $\begin{array}{l}\text { Have you been } \\
\text { in contact with } \\
\text { the clinic since } \\
\text { our last call? }\end{array}$ & Yes & $\begin{array}{l}0-6 \text { months } \\
>2 \text { years }\end{array}$ & $\begin{array}{l}34(1,024 / 2,993) \\
14(243 / 1,758)\end{array}$ \\
\hline $\begin{array}{l}\text { How well } \\
\text { informed } \\
\text { do you feel? }\end{array}$ & $\begin{array}{l}\text { Extremely } \\
\text { or very }\end{array}$ & $\begin{array}{l}0-6 \text { months } \\
>2 \text { years }\end{array}$ & $\begin{array}{l}59(1,764 / 3,004) \\
63(1,097 / 1,755)\end{array}$ \\
\hline $\begin{array}{l}\text { Have you } \\
\text { contacted any } \\
\text { support lines } \\
\text { this month? }\end{array}$ & No & $\begin{array}{l}0-6 \text { months } \\
>2 \text { years }\end{array}$ & $\begin{array}{l}94(2,826 / 3,012) \\
99(1,739 / 1,765)\end{array}$ \\
\hline \multicolumn{4}{|c|}{ Treatment experience } \\
\hline $\begin{array}{l}\text { How have you } \\
\text { been since the } \\
\text { last call? }\end{array}$ & $\begin{array}{l}\text { Very well } \\
\text { or well }\end{array}$ & $\begin{array}{l}0-6 \text { months } \\
>2 \text { years }\end{array}$ & $\begin{array}{l}24(726 / 3,017) \\
24(423 / 1,770)\end{array}$ \\
\hline $\begin{array}{l}\text { How have you } \\
\text { found taking } \\
\text { your treatment } \\
\text { this month? }\end{array}$ & $\begin{array}{l}\text { Very good } \\
\text { or good }\end{array}$ & $\begin{array}{l}0-6 \text { months } \\
>2 \text { years }\end{array}$ & $\begin{array}{l}24(729 / 3,016) \\
23(404 / I, 77 I)\end{array}$ \\
\hline $\begin{array}{l}\text { What was your } \\
\text { concern? }\end{array}$ & $\begin{array}{l}\text { Problems } \\
\text { with injecting } \\
\text { Other }\end{array}$ & $\begin{array}{l}0-6 \text { months } \\
>2 \text { years } \\
0-6 \text { months } \\
>2 \text { years }\end{array}$ & $\begin{array}{l}46(42 / 91) \\
50(9 / 18) \\
4 I(37 / 9 I) \\
44(8 / 18)\end{array}$ \\
\hline
\end{tabular}

\section{Treatment experience}

At the start of the study, 76\% (486/637) of patients for whom responses were available had concerns about starting treatment; the two most commonly reported concerns were the ability to self-inject (32\% [202/637]) and potential side effects $(28 \%$ [179/637]). Following the first delivery of sc IFN $\beta-1 \mathrm{a}, 73 \%(818 / 1,120)$ of patients reported that they had no concerns. Responses to treatment experience questions prior to the repeat delivery of sc IFN $\beta$-1a are shown in Table 2. Of the patients who ended treatment, the three most commonly reported reasons for stopping sc IFN $\beta$-1a treatment were side effects (28\% [100/355 responses]), hospital decision made by the patient's neurology team rather than by the patient (22\% [78/355 responses]), and switching therapy (21\% [73/355 responses]). The most common response to "What would be of most benefit to new patients?", from those who discontinued therapy, was "reducing the side effects of sc IFN $\beta-1 \mathrm{a}$ ” (48\% [124/261 responses]).

\section{Predictors of treatment discontinuation (new patients)}

In the univariate model, none of the candidate variables tested were significant predictors of treatment discontinuation
(Supplementary materials [Figures S1A-F]; $P>0.05$ for each variable; log-rank test), although trends were observed. Patients who had not received information about treatment from their clinic at pre-installation tended to discontinue treatment sooner than informed patients $\left(\chi^{2}=3.68\right.$, degrees of freedom $[d f]=1 ; P=0.055$; Figure 2A). Patients who felt extremely, very, or OK informed at pre-installation tended to discontinue treatment later than patients who answered not very $\left(\chi^{2}=6.24, d f=4 ; P=0.182\right.$; Figure $\left.2 \mathrm{~B}\right)$. Younger patients appeared to stop treatment earlier than patients in other age groups ( $\chi^{2}=7.44, d f=5 ; P=0.190$; Figure $\left.2 \mathrm{C}\right)$. Patients who felt very unwell on treatment tended to discontinue treatment earlier than those who felt not well, OK, very well, or well $\left(\chi^{2}=7.86, d f=4 ; P=0.097\right.$; Figure 2D).

In the multivariate model, the Cox regression analysis found that responses to the questionnaire items "Has your clinic given you any information on treatment yet?" (preinstallation) and "How have you been on treatment since our last call?" (very well, well, OK, not well, or very unwell; pre-delivery), and geographical region were all significant predictors of stopping treatment $(P<0.05$; Table 3$)$. Patients in Scotland were the most likely to discontinue treatment, compared with patients in the East of England.

\section{Information provision and treatment experience (new patients)}

A better treatment experience, denoted by a lower score (1-5), was seen during the first 6 months of therapy for patients who felt well informed at pre-installation ( $\mathrm{n}=973$; mean [SD] score 2.8 [0.5]) than those who felt less informed $(\mathrm{n}=158$; mean [SD] score: 2.9 [0.4]; $P=0.003)$. Patients who felt well informed during treatment reported significantly fewer problems taking their treatment $(\mathrm{n}=1135$; mean $[\mathrm{SD}]$ score: $2.7[0.4])$ than those who felt less informed $(\mathrm{n}=126$; mean [SD] score: $3.0[0.4] ; P<0.001)$. Patients felt that their level of information improved during the study compared with study outset $(P<0.001$ at each assessment), which was maintained for more than 2 years.

\section{Post hoc analyses (new patients)}

In multivariate analysis, deprivation (calculated using the Indices of Multiple Deprivation) was a significant predictor of treatment discontinuation for patients in England (hazard ratio $1.01,95 \%$ confidence interval $1.00-1.02, P=0.036$ ). In the univariate model, deprivation was not a significant predictor of treatment discontinuation for patients in England, Wales, or Scotland (Figure S2A-C). Patients who were given information by their clinic felt significantly better informed 

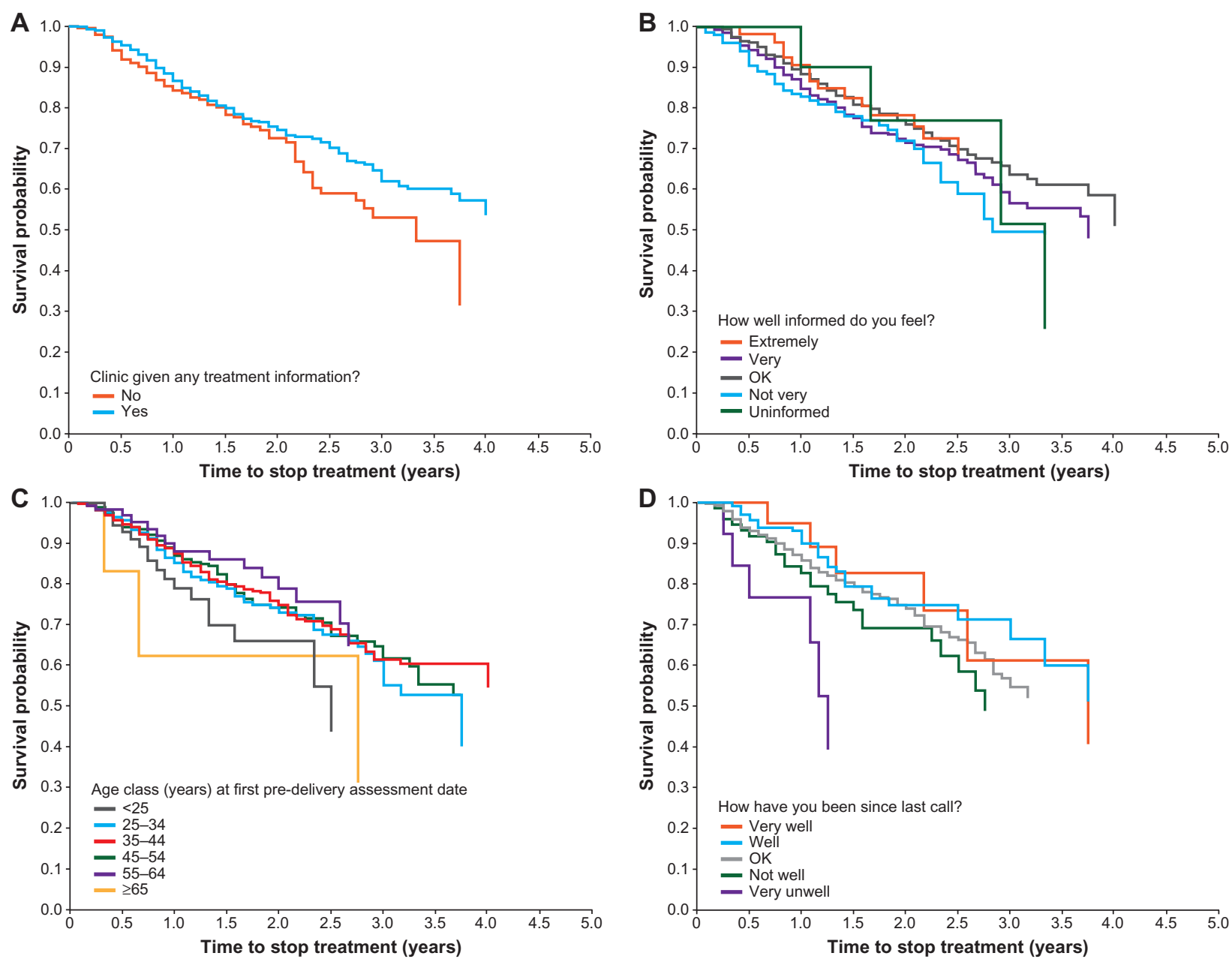

Figure 2 Kaplan-Meier curves of time to stop treatment within the new patient population, by: $(\mathbf{A})$ patients who received information from the clinic; (B) informed level at the outset; (C) age class at the start of treatment; (D) patient experience on treatment.

Table 3 Multivariate Cox regression analysis for time to stop treatment in new patients $(\mathrm{N}=1,267)$

\begin{tabular}{|c|c|c|c|c|}
\hline Covariate & $\mathbf{n}$ & $\begin{array}{l}\text { Hazard } \\
\text { ratio }^{\mathbf{a}}\end{array}$ & $95 \% \mathrm{Cl}$ & $P$-value \\
\hline \multicolumn{5}{|l|}{ Region } \\
\hline East of England & 106 & $1.00^{\mathrm{b}}$ & - & - \\
\hline East Midlands & 114 & 1.89 & $1.11-3.22$ & 0.020 \\
\hline Scotland & 100 & 2.81 & $1.60-4.94$ & $<0.001$ \\
\hline London & 55 & 1.63 & $0.76-3.48$ & 0.206 \\
\hline North East & 101 & 1.60 & $0.83-3.08$ & 0.160 \\
\hline North West & 177 & 1.68 & $1.02-2.76$ & 0.040 \\
\hline South Central & 108 & 2.09 & $1.23-3.57$ & 0.007 \\
\hline South East Coast & 55 & 1.03 & $0.47-2.23$ & 0.948 \\
\hline South West & 102 & 1.98 & $|| I-3.5 \mid$. & 0.020 \\
\hline West Midlands & 193 & 1.19 & $0.69-2.04$ & 0.537 \\
\hline Yorkshire and Humber & 156 & 1.47 & $0.87-2.49$ & 0.149 \\
\hline Has your clinic given you any & & 1.33 & $1.01-1.76$ & 0.045 \\
\hline \multicolumn{5}{|l|}{ information on treatment yet? } \\
\hline $\begin{array}{l}\text { How have you been on } \\
\text { treatment since our last call? }\end{array}$ & & 1.93 & $1.57-2.38$ & $<0.001$ \\
\hline
\end{tabular}

Notes: ${ }^{a}$ The hazard ratio for each effect tested is adjusted for all other covariates/

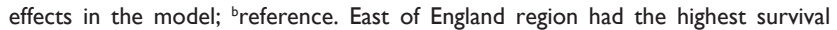
probability in the time to stop treatment analysis of all the regions studied; regions in bold were statistically more likely to stop treatment.

Abbreviation: $\mathrm{Cl}$, confidence interval. than patients who did not receive information $(P<0.001)$; however, provision of information by their clinic was not associated with the degree to which patients looked forward to therapy $(P=0.205)$.

\section{Discussion}

The AIMS study examined the risk factors related to premature treatment discontinuation and patients' experiences while receiving sc IFN $\beta$-1a. Provision of information at the outset of therapy, and whether patients had a favorable experience of treatment, were both found to have a positive influence on treatment persistence. The strongest predictor of treatment discontinuation was patients feeling unwell on treatment: the more patients felt unwell on treatment, the higher the likelihood of ending treatment. Geographical region, independent of social and economic deprivation, was also a strong predictor of treatment discontinuation, with patients in Scotland the most likely to discontinue treatment compared with patients in the East of England. 
Survival analyses of demographic and attitudinal variables measured at pre-installation were not predictors of early discontinuation, with curves diverging only after 2 years. Although it is not clear if the differences in information provision are clinically meaningful, patients who felt well informed at the study outset found that taking their therapy was a better experience for the first 6 months compared with the experience of those who felt less informed. In previous studies in patients with RRMS, the highest proportion of treatment interruptions occurred during the first 6 months. ${ }^{13}$ The number of new patients discontinuing therapy in this study $(24 \%)$ is higher than that observed in patients with RRMS treated under the UK risk-sharing scheme, ${ }^{14}$ but is comparable with discontinuation rates observed in retrospective studies. ${ }^{7,13}$

Observational data reflect populations and settings relevant to the environment in which clinicians and patients use therapy. The Association of the British Pharmaceutical Industry has acknowledged that real-world data on the use of medicine in normal clinical practice are becoming increasingly important in decisions affecting patients' access to medicines in the UK and worldwide. ${ }^{15}$ As such, the design of the AIMS study was considered to be most appropriate to assess the information on patients' treatment, including expectations, experience, training, and support. The AIMS program was a collaborative exercise among a pharmaceutical company, a homecare company, and the NHS to collect patient-centric, real-world data, which may stimulate new models of data collection and outcome research. The methodology utilized existing time points at which patients were contacted by homecare coordinators, using standard interview scripts to ensure consistency. A number of pharmaceutical agents are delivered in this manner, and a similar method to that used in the AIMS program could be employed to study the patients' experiences of these agents.

The study population included only patients receiving sc IFN $\beta$-1a who used Bupa Home Healthcare as their homecare provider and gave consent to participate in the study. Unlike a randomized controlled trial, patient consent involved verbal and written consent and not face-to-face communication. In addition, Bupa Home Healthcare was permitted, according to the study design approved by the ethics committee, to follow-up with patients only twice by telephone to obtain written consent. As only $49.9 \%$ of the patients approached to take part in the study provided written informed consent, the population was, to some degree, self-selecting for more motivated patients, possibly limiting the ability to identify factors related to premature treatment discontinuation.
A limiting factor in obtaining higher levels of written consent may have been the need for patients to return a copy of the consent form by mail.

Despite the large sample size, the physician-derived questionnaire that was developed expressly for this study may have contained a certain degree of bias, as patients were only involved in ensuring that the questionnaire language was clear and comprehensible, and not in suggesting or developing the questions. In addition, the questions may not have captured all of the domains relevant to patients, as patients and physicians have different perspectives regarding key aspects of MS diagnosis and assessment, treatment adherence, and disease management. ${ }^{16,17}$ The use of an appropriate, validated patient-reported outcome (PRO) instrument would have been preferable as it is recognized that patients' views of their own health, measured using a PRO, provide important and relevant assessments of the effects of treatment. ${ }^{15}$ The availability of sc IFN $\beta$-1a for several years prior to the start of this study may have been a confounding factor, as information and support would have been available from a number of sources. Additional factors affecting persistence to therapy may have been discerned with a drug new to the market, for which the patient materials and homecare delivery systems may not have been as developed and well established as studied here. Although not assessed in this study, advances in the injection technique for the administration of sc IFN $\beta-1 \mathrm{a}^{18}$ and the formulation of sc IFN $\beta-1 a^{19}$ have changed since the start of the study, which may have affected preference and acceptability of, and persistence to, treatment. Perceived lack of efficacy has been associated with IFN- $\beta$ treatment discontinuation, ${ }^{20-22}$ which was not directly assessed in this study. In future studies, identifying additional factors predictive of treatment discontinuation will be important, especially in patients receiving treatment for more than 2 years.

Low recruitment numbers in London and the South West, and late recruitment problems in London and Scotland, may have resulted in under-representation of these regions in the overall study population. The number of patients from Scotland included in the study was lower than in the rest of the UK. With only eleven MS centers in Scotland, the number and location of study centers, including differences in how the centers configure their services, may have affected regional differences in the hazard of stopping treatment; however, these factors were not identified by the current study. It could be speculated that socioeconomic factors may have influenced the risk of discontinuation in Scotland versus the East of England. However, although deprivation was a significant predictor of treatment discontinuation for patients 
in England, the effect size was close to 1.00, suggesting that the result may not be clinically relevant.

Home delivery of sc IFN $\beta$-1a therapy is a good example of the complementary roles of the NHS MS center team and the homecare delivery company when collaborating to maximize patients' adherence to therapy. The results of this study support the point that patients feeling unwell on treatment should be encouraged to contact available MS support services. All therapeutic interventions need to focus on supporting patients' confidence in self-management and enhancing their understanding of the disease and its treatment. In addition, at pre-delivery, patients should be asked if they are experiencing adverse effects; this should be communicated to the MS specialist nurse, who can then follow-up with the patients. Since the start of this study, support websites and telephone lines have been set up, along with field-based nurse support in certain locations, to further support patients and complement the service provided by the NHS MS centers, particularly in relation to injectable therapy. It may also be possible, when delivering the treatment, to include a prompt card that details the support services available. This could be an inexpensive intervention for patients who feel unwell or experience persistent adverse effects on treatment.

\section{Conclusion}

Overall, this study suggests that the provision of high-quality information and feeling well on treatment are the main determinants of persistence with sc IFN $\beta$-1a therapy in patients with MS. A package of care should therefore be considered when initiating sc IFN $\beta$-1a therapy.

\section{Acknowledgments}

The authors thank Tony Felton, Lal Ashby, Satellite for data management and analysis, Complete Regulatory Writing for preparing the clinical study report, and John Wiltshire and Dominic Jack of Caudex Medical, Oxford, UK (supported by Merck Serono Ltd, UK, an affiliate of Merck KGaA, Darmstadt, Germany, and Bupa Home Healthcare, Harlow, Essex, UK), for assistance in the preparation of this manuscript. This study was supported by Merck Serono Ltd, UK, an affiliate of Merck KGaA, Darmstadt, Germany; and Bupa Home Healthcare, Harlow, Essex, UK.

\section{Author contributions}

MS was involved in the design of the analysis, interpretation of data and review of the manuscript. DR was involved in the planning of the statistical analysis and the composition of, and revisions to, the manuscript. LP was involved in study management, critically revising and approving the manuscript. GLS was involved in design, advising on conduct of study, analysis and interpretation of data, and reviewing the manuscript. All authors gave final approval of the version for publication.

\section{Disclosure}

MS was an employee of Bupa Home Healthcare, Essex, UK, at the time of the study. DR has received honoraria, and/or speaking fees, and/or support to attend meetings and/or served on advisory boards for the following companies: Merck Serono, Biogen Idec, Sanofi, Teva Pharmaceuticals, Genzyme, Novartis, Bayer Schering and Pfizer. LP and GLS were employees of Merck Serono Ltd, UK, at the time of the study.

\section{References}

1. Bennett JL, Stüve O. Update on inflammation, neurodegeneration, and immunoregulation in multiple sclerosis: therapeutic implications. Clin Neuropharmacol. 2009;32(3):121-132.

2. Hauser SL, Oksenberg JR. The neurobiology of multiple sclerosis: genes, inflammation, and neurodegeneration. Neuron. 2006;52(1):61-76.

3. Lublin FD, Reingold SC. Defining the clinical course of multiple sclerosis: results of an international survey. National Multiple Sclerosis Society (USA) Advisory Committee on Clinical Trials of New Agents in Multiple Sclerosis. Neurology. 1996;46(4):907-911.

4. Hartung HP. High-dose, high-frequency recombinant interferon beta-1a in the treatment of multiple sclerosis. Expert Opin Pharmacother. 2009;10(2):291-309.

5. World Health Organization. Adherence to Long-Term Therapies: Evidence for Action. Geneva: World Health Organization; 2003. Available from: http://www.who.int/chp/knowledge/publications/adherence_full_report.pdf. Accessed March 22, 2013.

6. Río J, Porcel J, Téllez N, et al. Factors related with treatment adherence to interferon beta and glatiramer acetate therapy in multiple sclerosis. Mult Scler. 2005;11(3):306-309.

7. O'Rourke KE, Hutchinson M. Stopping beta-interferon therapy in multiple sclerosis: an analysis of stopping patterns. Mult Scler. 2005;11(1):46-50.

8. Cox D, Stone J. Managing self-injection difficulties in patients with relapsing-remitting multiple sclerosis. J Neurosci Nurs. 2006;38(3): 167-171.

9. Tan H, Cai Q, Agarwal S, Stephenson JJ, Kamat S. Impact of adherence to disease-modifying therapies on clinical and economic outcomes among patients with multiple sclerosis. Adv Ther. 2011;28(1):51-61.

10. Lugaresi A. Addressing the need for increased adherence to multiple sclerosis therapy: can delivery technology enhance patient motivation? Expert Opin Drug Deliv. 2009;6(9):995-1002.

11. Rebif Summary of Product Characteristics [webpage on the Internet]. UK: Datapharm Communications, Ltd; 2013. Available from http:// www.medicines.org.uk/EMC/medicine/22392/SPC/Rebif solution for injection in pre-filled syringes/. Accessed March 22, 2013.

12. Heeren T, D'Agostino R. Robustness of the two independent samples $t$-test when applied to ordinal scaled data. Stat Med. 1987;6(1): 79-90.

13. Tremlett HL, Oger J. Interrupted therapy: stopping and switching of the beta-interferons prescribed for MS. Neurology. 2003;61(4):551-554.

14. Boggild M, Palace J, Barton P, et al. Multiple sclerosis risk sharing scheme: two year results of clinical cohort study with historical comparator. BMJ. 2009;339:b4677. 
15. http://www.abpi.org.uk/Pages/default.aspx [homepage on the Internet]. Association of the British Pharmaceutical Industry. Demonstrating Value with Real World Data. 2011. The Association of the British Pharmaceutical Industry; 2011. Available from: http://www.abpi.org. uk/our-work/library/guidelines/Pages/real-world-data.aspx. Accessed March 22, 2013.

16. Rothwell PM, McDowell Z, Wong CK, Dorman PJ. Doctors and patients don't agree: cross sectional study of patients' and doctors' perceptions and assessments of disability in multiple sclerosis. BMJ 1997;314(7094):1580-1583.

17. Riñon A, Buch M, Holley D, Verdun E. The MS Choices Survey: findings of a study assessing physician and patient perspectives on living with and managing multiple sclerosis. Patient Prefer Adherence. 2011;5:629-643.

18. Exell S, Verdun E, Driebergen R. A new electronic device for subcutaneous injection of IFN- $\beta$-1a. Expert Rev Med Devices. 2011;8(5): $543-553$.
19. Giovannoni G, Barbarash O, Casset-Semanaz F, et al; Rebif New Formulation Study Group. Safety and immunogenicity of a new formulation of interferon $\beta$-1a (Rebif $^{\circledR}$ New Formulation) in a phase IIIb study in patients with relapsing multiple sclerosis: 96-week results. Mult Scler. 2009;15:219-228.

20. Beer K, Müller M, Hew-Winzeler AM, et al. The prevalence of injectionsite reactions with disease-modifying therapies and their effect on adherence in patients with multiple sclerosis: an observational study. $B M C$ Neurol. 2011;11:144.

21. Mesaroš S, Stojsavljević N, Dujmović-Bašuroski I, Dejanović I, Pekmezović T, Drulović J. Long-term adherence to interferon-beta treatment in a cohort of RRMS patients in Belgrade, Serbia. Clin Neurol Neurosurg. 2012;114(8):1145-1148.

22. Vicente Iturbe C, Ara Callizo JR, Huarte Lacunza R, Navarro Aznárez H, Serrano Mislata N, Rabanaque Hernández MJ. [Discontinuation and long-term adherence to beta interferon therapy in patients with multiple sclerosis]. Farm Hosp. 2012;36(2):77-83. Spanish.
Patient Preference and Adherence

\section{Publish your work in this journal}

Patient Preference and Adherence is an international, peer-reviewed, open access journal focusing on the growing importance of patient preference and adherence throughout the therapeutic continuum. Patient satisfaction, acceptability, quality of life, compliance, persistence and their role in developing new therapeutic modalities and compounds to

\section{Dovepress}

optimize clinical outcomes for existing disease states are major areas of interest. This journal has been accepted for indexing on PubMed Central. The manuscript management system is completely online and includes a very quick and fair peer-review system. Visit http://www.dovepress.com/ testimonials.php to read real quotes from published authors.

Submit your manuscript here: http://www.dovepress.com/patient-preference-and-adherence-journal 